\title{
VELOCIDADE DE CRESCIMENTO E DESENVOLVIMENTO SEXUAL DE RATAS SUBMETIDAS A DIFERENTES GRAUS DE RESTRIÇĀO ALIMENTAR.
}

\author{
Leda Ulson Mattos* \\ Hisako Kajiyama** \\ Sandra Megrich *** \\ Margareth Knoch*** \\ Ruth Silvia Steuer***
}

MATTOS. L. U., KAJTYAMA. H., MEGRICH. S., KNOCH. M, STEUER. R S. Velocidade de crescimento e desenvolvimento sexual de ratas submetidas a diferentes graus de restriçāo alimentar. Rev. Esc. Enf. USP, São Paulo, 18(2):121-127, 1984.

As autoras estudaram em dois grupos de ratas com restrição alimentar, que recebiam, respectivamente, $6 \mathrm{~g}$ dia e $4 \mathrm{~g}$ dia de uma dieta com $20 \%$ de proteina da caseina, a idade $e$ o peso dos animais na abertura da vagina e no 19 estro. A média de peso dos animais nos 2 grupos nōo diferiram, significativamente, da do grupo controle, embora os primeiros apresentassem maturaçđo sexual mais tardiamente que ou último.

\section{INTRODUÇÃO}

FRISCH \& REVELLE (1970) e FRISCH (1972) demonstraram que o peso médio, na época da menarca, de adolescentes malnutridos não diferia significativamente do das bem-nutridas, apesar de as primeiras atingirem a menarca mais tarde que as segundas, levantando a hipótese da existência de um peso crítico no qual a menarca é atingida.

Em animais, DICKERSON et alii (1964) comprovaram, em porcas, e KENNEDY \& MITRA (1963) e WINDDOWSON \& Mc CANCE (1960), em ratas, a hipotese de FRISCH \& REVELLE (1970).

Posteriormente, FRISCH modificou sua hipótese, admitindo que, para alcançar a menarca, as adolescentes teriam que atingir determinada percentagem de gordura corporal (FRISCH, 1980; FRISCH e McARTHUR, 1974; FRISCH, 1974; FRISCH \& REVELLE, 1970; FRISCH et alii, 1973).

* Professor Tttular do Departamento de Enfermagem Médico-Cirírgica da Escoln de Enfermagem da USP - disciplina Nutriçio e Dietética Aplicadas à Enfermagem.

* Professor Assistente do Departamento de Enfermagem Manterno-Infantil e Psiquiátrica da Escola de Enfermagem da USP - disciplina Enfermagem Obstétrica e Ginecológica.

*** Estudante do Curso de Graduacío da Escola de Enfermagem da USP. 
Recentemente tem havido críticas sobre as duas hipóteses de FRISCH, a de peso crítico e a de composição corporal constante \& (OSLER \& CRAWFORD, 1973; CRAWFORD e OSLER, 1975; JOHNSTON et alii, 1971).

MATTOS et alii (1979), GLASS et alii (1976), WILEN \& NAFTOLIN (1978) já haviam estudado e encontrado relação entre a velocidade de crescimento e a idade do estro em ratas, concordando que a idade do animal no estro é uma função linear negativa da velocidade de crescimento.

Em razão das controversias existentes em relação às duas hipóteses, resolvemos reestudar o assunto, observando o comportamento sexual de ratas submetidas a dois graus de restrição alimentar.

\section{MATERIAL E METODO}

\section{Material}

Como animais de experiência foram utilizadas 60 ratas (Rattus norwegicus, albinus, Wistar), recém-desmamadas, aos 21 dias de idade, criadas no biotério da Esçola de Enfermagem da USP.

A temperatura do biotério foi mantida entre 24 e $26^{\circ} \mathrm{Ce}$ as luzes foram apagadas no período das $18 \mathrm{~h}$ às 7 horas.

A dieta utilizada continha $20 \%$ de proteína da caseína, 381 calorias por $100 \mathrm{~g}$ de dieta e apresentava a seguinte composição percentual:

Composição Percentual das Dietas Utilizadas

\begin{tabular}{lc}
\hline Componentes & g/150g de Dieta \\
\hline Caseína & 26,8 \\
Amido & 40,8 \\
Oleo de Algodz̃o & 6,0 \\
Oleo de Fígado de Bacalhau & 1,6 \\
Mistura de Sais Minerais** & 3,6 \\
Mistura de Vitaminas*** & 1,6 \\
Af̧úcar & 20,0 \\
\hline
\end{tabular}

* Teor Protéico da Caseína - 75,6\%

** PHILLIPS \& HART (1935)

*** SCHAEFFER et alii (1949)

\section{Procedimento Experimental}

Os animais foram distribuídos ao acaso em 3 grupos de 15: o grupo controle (c) e os grupos experimentais I e II, sendo de $39 \mathrm{~g}$ o peso médio inicial 
das ratas de cada grupo. Os animais do grupo controle (c) receberam dieta "ad libitum" e os modelos I e II, a mesma dieta em quantidades restritas, $6 \mathrm{~g}, 4 \mathrm{~g} /$ dia respectivamente.

No período experimental o peso corporal dos animais e a quantidade da dieta ingerida pelo grupo controle foram registrados diariamente. $O$ dia da abertura da vagina e do 19 estro foi anotado, assim como o peso da rata nesse dia.

Para determinar o início do 10 estro, foi colhido material vaginal, diariamente, após abertura da vagina.

\section{RESULTADOS E DISCUSSÃO}

As retas de regressão do crescimento dos animais de cada grupo estão apresentadas na figura $I$.

Podemos observar que a velocidade de crescimento dos animais dos 3 grupos é diferente, conforme indica a tabela 1 ( $p<0,001$ ). Como podemos também verificar a idade no 19 estro é uma função linear negativa da velocidade de crescimento $(r=-0,95)$.

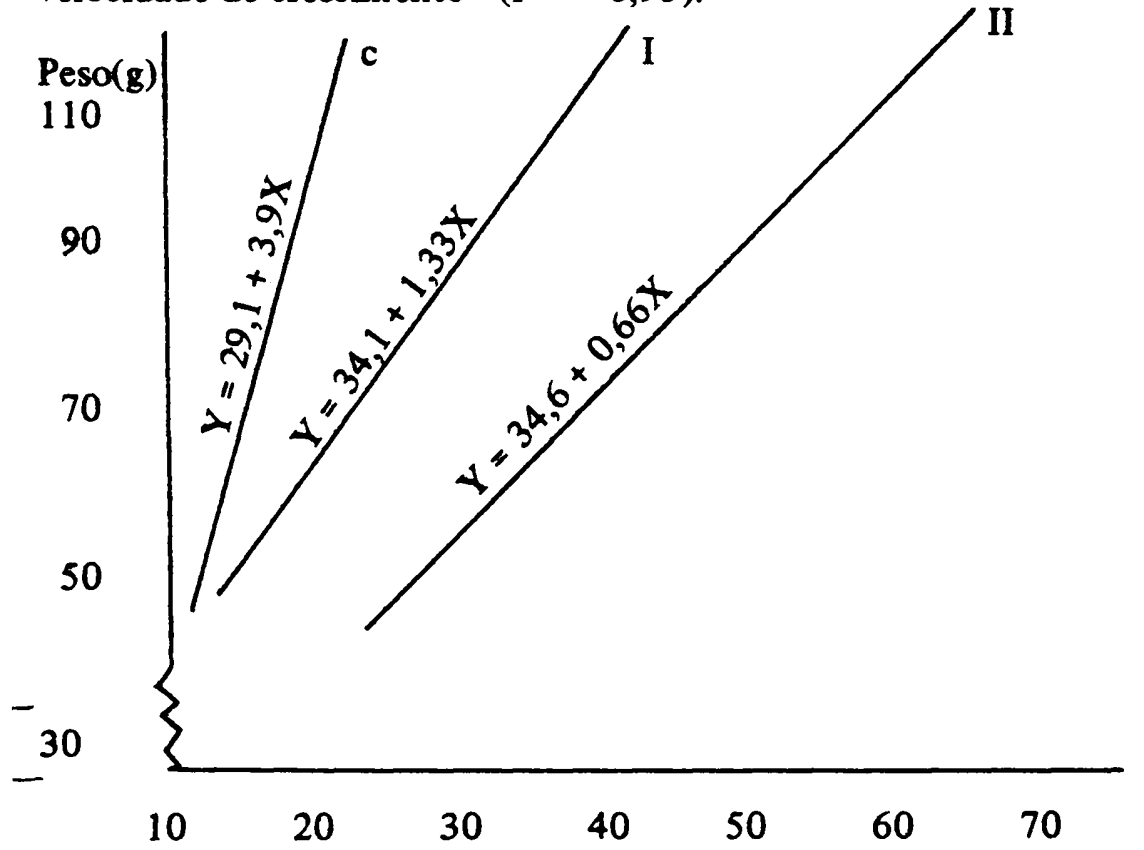

80 Dias

Figura 1 - Retas de regressão de crescimento de animais dos dois grupos experimentais e do grupo controle.

$\mathrm{Na}$ tabela 1 apresentamos os dados correspondentes à abertura da vagina e do 1 o estro. As diferenças săo altamente significativas $(p<0,001)$ em rela- 
Tabela 1 - Velocidade de crescimento, idade e peso do animal no dia da abertura da vagina e do 10 estro.

\begin{tabular}{|c|c|c|c|}
\hline $\begin{array}{l}\text { Grupos } \\
\text { Variável }\end{array}$ & $\begin{array}{l}\text { Grupo } \\
\text { Controle }\end{array}$ & Grupo I & Grupo II \\
\hline \multicolumn{4}{|l|}{ Abertura da vagina } \\
\hline $\begin{array}{l}\text { Velocidade de } \\
\text { Crescimento (g/dia) }\end{array}$ & $\begin{array}{c}3,72 \\
(0,60)\end{array}$ & $\begin{array}{l}1,24 \mathrm{P}<0,001 \\
(0,36)\end{array}$ & $\begin{array}{cc}0,48 & \mathrm{P}<0,001^{*} \\
(0,22) & \mathrm{P}<0,001^{* *}\end{array}$ \\
\hline Idade (dias) & $\begin{array}{l}32,4 \\
(0,70)\end{array}$ & $\begin{array}{l}41,5 \\
(7,4)\end{array}$ & $\begin{array}{rl}73,2 & \mathrm{P}<0,001^{*} \\
(11,9) & \mathrm{P}<0,001^{* *}\end{array}$ \\
\hline Peso (G) & $\begin{array}{l}76,7 \\
(9,3)\end{array}$ & $\begin{array}{l}\text { 67,6 N.S.* } \\
(15,2)\end{array}$ & $\begin{array}{cl}65,4 & \text { N. S.* } \\
(10,4) & \text { N. S.** }\end{array}$ \\
\hline \multicolumn{4}{|l|}{ 10 Estro } \\
\hline $\begin{array}{l}\text { Velocidade de } \\
\text { Crescimento (g/dia) }\end{array}$ & $\begin{array}{r}3,97 \\
(0,6)\end{array}$ & $\begin{array}{l}1,22 \mathrm{P}<0,001 * \\
(0,36)\end{array}$ & $\begin{array}{cc}0,41 & P<0,001^{*} \\
(0,22) & P<0,001^{* *}\end{array}$ \\
\hline Idade (dias) & 33,2 & $55,5 \quad \mathrm{P}<0,001^{*}$ & $101,2 \quad P<0,001^{*}$ \\
\hline Peso (g) & $\begin{array}{l}80.8 \\
(10,7)\end{array}$ & $\begin{array}{l}86,8 \text { N. S.* } \\
(12,7)\end{array}$ & $\begin{array}{l}71,9 \text { N. S. }{ }^{*} \\
17,11 \text { N. S. }{ }^{* *}\end{array}$ \\
\hline
\end{tabular}

N. S. não significativa

* entre os grupos I, II e o controle

** entre os grupos I e II.

ção à velocidade de crescimento nos 3 grupos, para a idade na abertura da vagina, e para o 1 ọ estro, mas não são significativas no que concerne ao peso.

Como vemos, nas ratas com ótimo desenvolvimento não há diferença significativa entre a idade da abertura da vagina e do 1 o estro, o que ocorre em ratas com dieta restrita em quantidade de alimentos. lsso já havia sido mostrado por KENNEDY \& MITRA (1963) em ratas com crescimento moderado e muito retardado.

$\mathrm{Na}$ tabela 2 estão apresentados os valores relativos à variação de peso, alimento, proteína e calorias consumidas.

Pela Tabela 2 vemos que năo há diferença significativa na variação de peso, o que indica que, embora a velocidade de crescimento e a idade no 1 o estro seja diferente, as ratas atingiram maturação sexual com o mesmo peso.

Nós encontramos uma relação linear altamente significativa $(r=-0,95$ e $p<0,001$ ) entre a idade na puberdade e a velocidade de crescimento das ratas em restriçâo alimentar. A correlação linear entre a velocidade de cres- 
Tabela 2 - Variação ponderal, alimento e proteína ingerida, calorias consumidas do desmame até o 1 ọ estro.

\begin{tabular}{|c|c|c|c|}
\hline Grupo Varifivel & Controle & I & II \\
\hline $\begin{array}{l}\text { Variação de } \\
\text { Peso (g/dia) }\end{array}$ & $\begin{array}{l}47,0 \\
(5,4)\end{array}$ & $\begin{array}{l}44,0 \text { N. S.* } \\
(12,3)\end{array}$ & $\begin{array}{l}33,1 \text { N. S.* } \\
(9,0) \text { N. S.** }\end{array}$ \\
\hline $\begin{array}{l}\text { Alimento Ingerido } \\
(\mathrm{g} / \mathrm{dia})\end{array}$ & $\begin{array}{c}9,6 \\
(1,5)\end{array}$ & 6,0 & 4,0 \\
\hline $\begin{array}{l}\text { Proteína Ingerida } \\
\text { (g/dia) }\end{array}$ & $\begin{array}{c}1,9 \\
(0,4)\end{array}$ & 1,2 & 0,8 \\
\hline $\begin{array}{l}\text { Calorias Consumidas } \\
\text { (cal/dia) }\end{array}$ & $\begin{array}{l}36,4 \\
(3,6)\end{array}$ & 22,8 & 15,2 \\
\hline
\end{tabular}

N. S. não significativa

* entre grupos I, II e o controle

** entre grupos I e II.

cimento e a idade já havia sido descrita em camundongos por MONTEIRO \& FALCONER (1966) e por GLASS et alii (1976) e em ratos por WILEN \& NAFTOLIN (1978) e MATTOS et alii (1979).

GLASS et alii (1976) verificaram que o peso do animal na época da maturação sexual não era constante, mas funcionava como uma função quadrática da velocidade de crescimento. KENNEDY \& MITRA (1963) e MANDL \& ZUCKERMAN (1952) mostraram que o peso na puberdade não era constante em diferentes condiçбes, e que podia variar segundo fatores genéticos e fatores ambientais, como temperatura e luz.

Nossos resultados indicativos de que ratas com restrição alimentar crescem com velocidade diferente, mas que abrem a vagina e atingem o 1 o estro com o mesmo peso estão em concordância com os trabalhos de DICKERSON et alii (1964) e WILEN \& NAFTOLIN (1978); estão, também de acordo com a idéia de que populaçð̃es de várias médias de idade atingem o mesmo "peso demográfico" na puberdade (WILEN \& NAFTOLIN, 1976).

\section{CONCLUSÕES}

Foram determinados os pesos corporais, por ocasião do desmame, no dia da abertura da vagina e no 10 estro de 30 ratas com 2 graus de restrição alimentar. Esses resultados foram comparados com os do grupo controle e nos permitiram concluir que:

- A idade em que ocorre o 10 estro é função linear negativa da veloçidade de crescimento dos animais $(r=-0,95)$. 
- Não há diferença significativa entre o peso dos animais ao abrirem a vagina ou atingirem o 19 estro nos 3 grupos controle e de restrição alimentar.

- Os animais dos grupos restritos atingiram a maturação sexual (10 estro) mais tardiamente: Grupo I ( $6 \mathrm{~g} / \mathrm{dia})$, aos 55,5 dias, e Grupo II (4g/dia), aos 101,2 dias. No Grupo Controle o 1 o estro ocorreu nas ratas com 32,4 dias de idade em média.

- como podemos verificar, os nossos resultados parecem concordar com a hipótese de FRISCH \& REVELLE (1970) de que existe um peso crítico no qual a menarca é atingida, embora as adolescentes bem nutridas atinjam a menarca mais jovens.

MATTOS. L. U.; KAJIYAMA. H.; MEGRICH. S.; KNOCH. M.; STEUER. R. S. Growth rate and development in feed restricted female rats. Rev. Esc. USP. 18(2):121-127, 19844

Age and weight were determined by direct measure in 30 feed-restnctea female rats studied from weaning to first estrus, and compared to well fed controls. At the first estrus the average weight of well fed rats did not differ from that of the feed-restricted groups.

Mean ages at vaginal opening and first estrus in the feed-restricted animals were however greater.

\section{REFERÊNCIAS BIBLIOGRÁFICAS}

1. CRAWFORD, J.A. \& OSLER, D.C Body composition at menarche: the FRISCH-REVELLE hypothesis revisited. Pediatrics, Springfield, 56(3):449-58, 1975

2. DICKERSON, J. W. T.; GRESHAM, G. A.; MCCANCE, R. A The effect of undernutrition and rehabilitation on the development of the reproductive organs: pigs. J. Endocr. London, 29: $111-8,1964$.

3. FRISCH, R E. A method of prediction of age of menarche from height and weight at ages 9 trough 13 years. Pediatrics, Springfield, 53(3): 384-90, 1974.

4. Pubestal adipose tissue: is it necessary for normal sexual maturation? Evidence from the rat and human female. Fed. Proc. Washington, 39:2395-400, 1980.

5.

Weight at menarche; similarity for well-nourished and undernourished girls at differing ages and evidence for historical constancy. Pedistrics, Springfield, 50(3):445, 450, 1972.

6.

\& MCARTHUR, J. W. Menstrual Cycles: fatness as a determinant of minimun weigth and height necessary for their maintenance or onset. Science, Washington, 185:949$-51,1974$.

7.

\& REVELLE, R. Height and weigth at menarche and a hypothesis of critical body weights and adolescent events. Science, Washington, 169:397, 399, 1970.

8.

; REVELLE. R.; COOK. S. Components of weight at menarche and initiation of the adolescent growth spurt in girls: estimated total water and lean body weight fat. Hum Biol Muchigan 45(3):469-83, 1973.

9. GLASS, A. R; HARRISON, R.; SWERDLOFF, R. S. Effect of under nutrition and amino acid deficiency on the timing of puberty in rats, Pediat. Res. Basel, 10:951-5, 1976. 
10. JOHNSTON, F. E.; MALINE, R. M.; GALBRAITE, M A. Height, weigth and age at menarche and the "critical weight", hypothesis. Science, Washington, 174:1148, 1971.

11. KENNEDY, G. C. \& MTTRA, J. Body weight and food intake as initiating factors for puberty in the rat. J. Physiol, London, 166:408-18, 1963.

12. MANDL, A. M. \& ZUCKERMAN, S. Factors influencing the set of puberty in albino rats. J. Endocr., London, 8:357-64, 1952.

13. MATTOS, L U.; KAITYAMA, H. ANNUNCIATO, N. F.; MARQUES, M. R. Velocidade de crescimento e desenvolvimento sexual de ratas submetidas a desnutriçío proteico-calórica. Rev. Esc. Enf. USP, Sto Paulo, 13(3):251-59, abr. 1979.

14. MONTEIRO, L S. \& FALCONER, D. S. Compensatory, growth and sexual maturity in mice. Anim. Prod. Edinburgh, 8:179-92, 1966.

15. OSLER, D. C. CRAWFORD, J. A. Examination of the hypothesis of a critical weight at menarche in ambulatory and bedridden. mentally retarded sirls. Podintrice, Springfield, S1(4):675, 679, 1973.

16. PHIILIIPS, P. H \& HART, E. B. The effect of organic dietary constituints upon chronic fluarine toxicoses in the nat. J. Biol. Chem, Baltimore, $109(1): 657-63,1935$.

17. SCHAEFFER, A. E.; SALMON, W. D.; STRENGTH, D. R. Interrelntionship of vitumin B. 12 and choline $I$. effect on hemomaic Kidney syndrome in the rat. Proc Soc Exp. Diol, New Yort $71: 193,1949$.

18. WDDOWSON, E \& Mc CANCE, R. A. Some effects of accelenting growth I: General somatic developinent. Foc. roy. Soc. London 152: 188, 1960.

19. WILEN, R \& NAFTOLN, F. Pubertal food intake and body lenth, weight and componition in the feed-rectricted female ret; comparion with well fod animats Fodint. Ros, Basel, 12:263-7, 1978.

20.

Ape Weint and Weight orin in the individual pubertal formale rheass monkey (macaca molata) Bhal Repr. Now York, 15:35660, 1976. 